\title{
Sobre o teatro de marionetes
}

Tradução, apresentaçảo e nolas de J. GUINSBURG

Sobre as marionetes de Kleist

Escritopara o Berliner Abendblätter, um diärio berlinense fundado por Heinrich von Kleist (1777-1811), apareceu em quatro folhetins estampados de 12 a 15 de dezembro de 1810. Otexto "Sobreo Teatrode Marionetes" näotève grande repercussãona época nè ao longo do século XIX. Sua sorte mudou somente noséculo XX, quando a crítica comȩ́ou a utilizá-lo como uma das chaves para a interpretação da obra dramática e do universo ficcionaldoautor de A Bilha Qucbrada, Pentesiléia e Principe Frederico de Hamburgo.

Mas foi, sem dávida, a partir do simbolismo

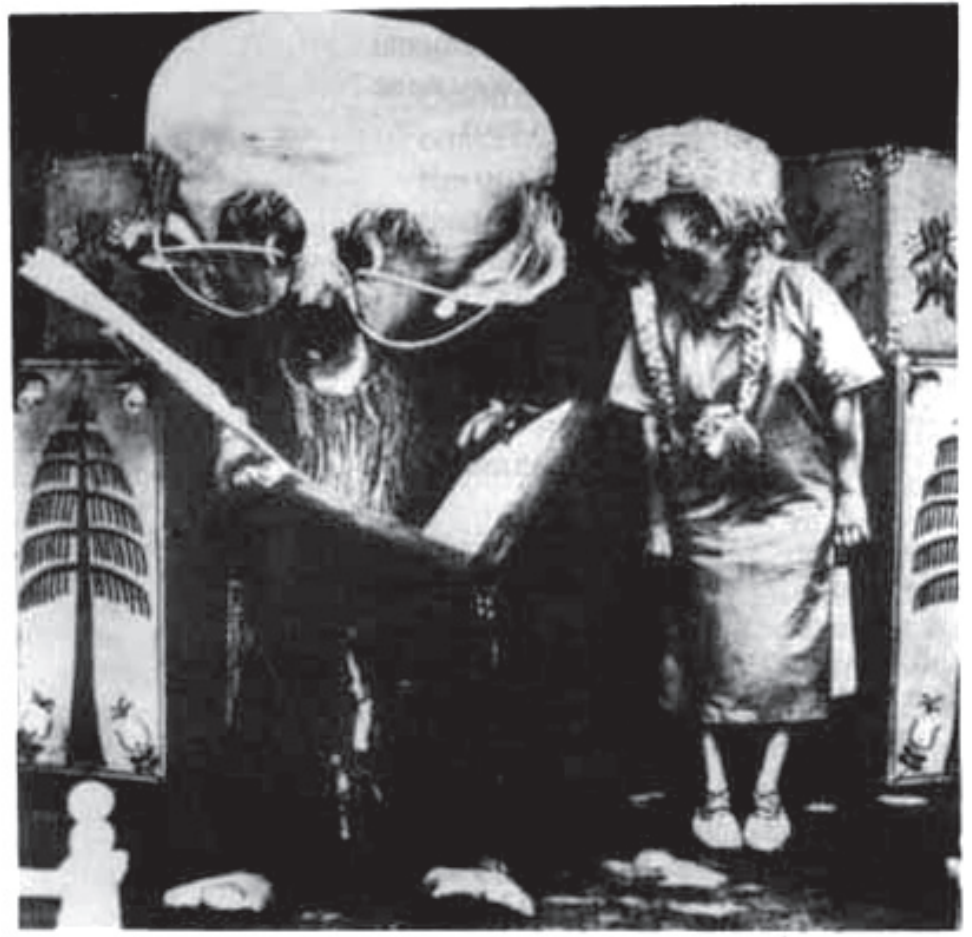
e doexpressionismoque as buscasestéticas da modernidade fizeram incidiruma luz par. ticular sobre a reflexão desenvolvida neste escrito acerca da natureza da graça e do movimento no títere e na daņ̧a, do gesto e de sua representaçāo no teatro, bem como da harmonia e da consciência no homem, vistos na perspectiva romântica - a de um intento paradoxal de recuperar uma originalidade e perfeição absolutas perdidas para sempre, na história humana, à porta do Paraíso.

Trata-se de am absolutoque, para Kleist, só pode residir ou em algo que "näo tem consciência nenhuma ou tem uma consci. ćncia infinita, isto é, no manequim ou cm Deus".

De fato, unicamente o automatismo do movimento mecânico (o da marionete) ou do movimento instintivo (o do animal) ou, de outra parte, a espontaneidade de um di. 


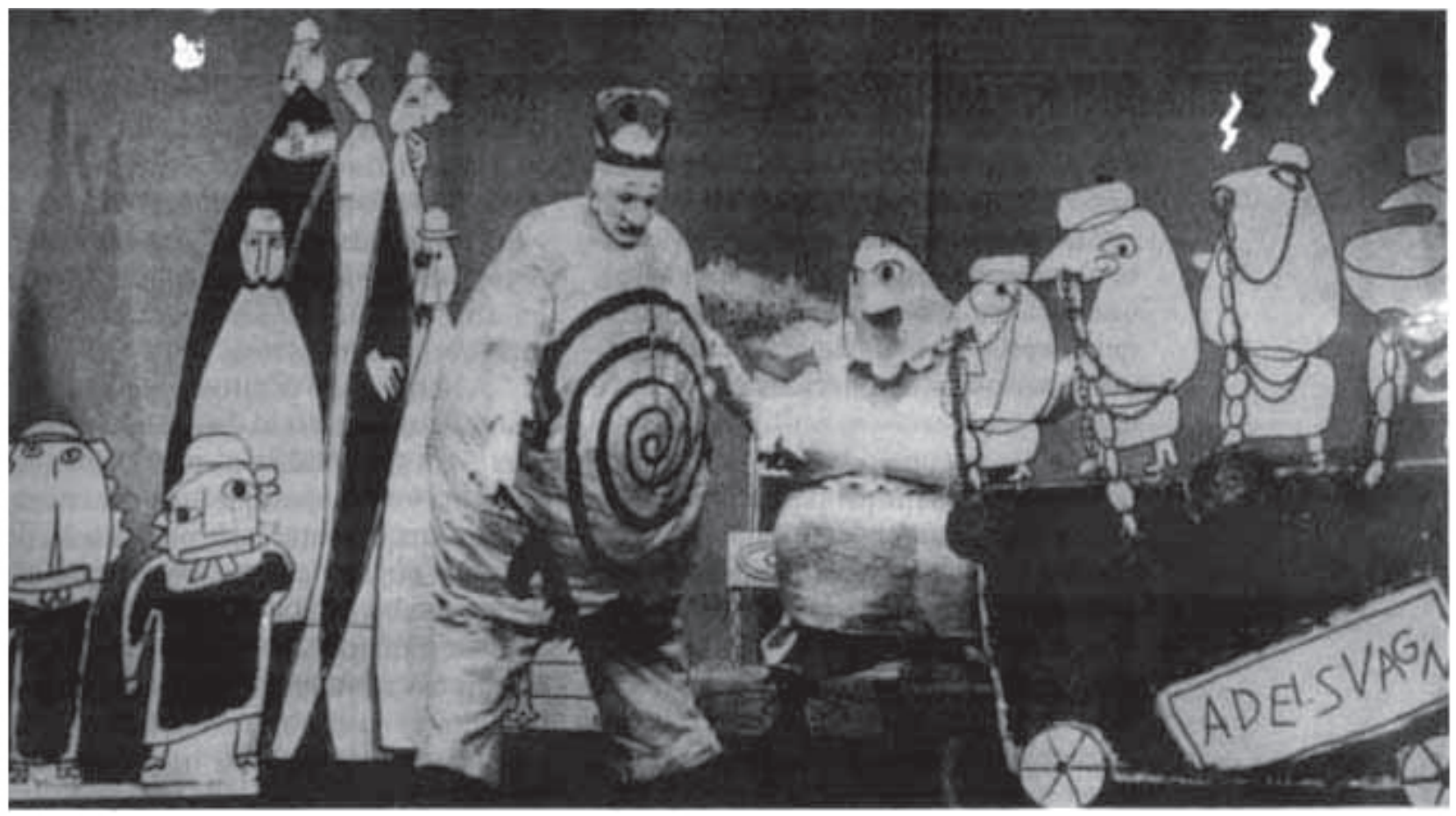

namismo e de um gesto nāo seccionados pela reflexividade representativa (no bailarino) seriam capazes de restituir toda a inteireza e pureza da expressão do espirito no corpo, ou seja, fazer presente a graça e com ela a beleza (a esteticidade) da materialização motogestual.

Ora, não é precisamente nisto que consiste a idéia da Supermarionete de Gordon Craig - oator expungido das carências de suas imperfeiçöes físicas, mentais e emocionais, dos "acidentes" da atuaçāo psicológica e realista, aptoa executar à perfeiçāo a encenação e a simbolizaçāo cênicas e, por seu intermédio, a obra de arté teatral?

Compreende-se, pois, que o autor de A Arte do Teatro (1911), a fim de ultrapassar radicalmente o naturalismo no palco, buscando uma estética da teatralidade como tal, enveredasse por um caminho que, se não derivou diretamente de seu antecessor, Kleist, apresenta inegável afinidade de percepçâo com ele.

É claro que a meditação do poeta alemão pode ser analisada, igualmente, como uma visão do destino paradoxal do teatro, que está condenado, justamente por sua convenção mimética e representativa, a perder o seu maior anseio e alvo, a revivência como vivência pura da dramaticidade no palco. Digamos que, a esta luz da cena teatral, o teatro foi banido, sem retorno possível, do Éden, do gesto original da espontaneidade e da autenticidade. Ou, para voltar ao início, ele só poderá recuperá-lo mediante a provaçāo de um novo fruto da árvore do conhecimento. Mas nãoterá sido isto que Stanislávskie Grotówski, por exemplo, tentaram, a seu modo? Querer responder à pergunta é refazer o percursoda história do teatro depois de expulso do rito primitivo... Como se vê, uma tarefa em círculo que remete aoadmirador judeu doextraviadooficial prussiano, von Kleist-Kafka. Poisvon Kleist, embebido de Kant e Rousseau, une-os numa conjugaçāo singular de idéia, em que a inacessibilidade da "coisa em si" e a subjetividade do conhecimento fazem do intelecto e da consciência fontes do erro e da ilusão a solapar e a alienar de modo irreversível, no curso do tempo e da história, a unidade edénica do homem adâmico e do seu universo de representação, posto que, em última análise, què está em foco, nas marionetes de Kleist, nâo é apenas o ator, o titereiro, o bailarino e o artista, porém o homem em cena, na vida.
A ESOUEADA, TEATRO LALEK (POLONIA, 1040) FOTO DE M. FPANKFUAT UNIMA. ACIMA MAPIONETTEATERN.

ULYSSES, FOTO DE 
Eu passava o invernode $1801 \mathrm{~cm}$ M..., quandoencontreicerta noite, $\mathrm{em}$ um jardim público, o $\mathrm{Sr}$. C., que, havia pouco, fora contratado, nessa cidade, como primeiro bailarinoda ópera, eque obtivera extraordinário êxito junto ao público.

Disse-lhe de meu espanto por tế-lovistovárias vezes em um teatro de marionetes, que fora armado na praça do mercado, $\mathrm{c}$ que divertia o poviléu com pequenas revistas burlescas, entretecidas de cançổes $\mathrm{c}$ danças.

Elemeassegurouqueaarte pantomímica desses bonecos the proporcionara muito prazer, e deu a entender, de mancira nada obscura, que um dançarino, desejoso de aperfeiçoar-se, poderia aprender muita coisa com eles.

Uma vez que essa declaração, dado o modopeloqual a proferiu, me pareceu algo mais do que mero capricho do momento, sentei-me a seu lado a fim de inquiri-lomais acuradamente sobre as razóes de táosingular assertiva.

Ele me perguntou se cu náo achara que alguns movimentos dos bonccos, particularmente dos menores, cram, na dança, sobremancira graciosos.

Eu nảo poderia negar cssa circunstância. Mesmo Teniers não poderia pintar melhor um grupo de quatro camponeses a bailar a ronda em compasso acelerado.

Quis inteirar-me domecanismodessas figuras, e perguntei comocra possivel, sem ter nos dedos miríades de fios, reger cada membro isolado e seus pontos, tal comoo ritmo do movimento, ou da dança, exigia.

Ele me respondeu que cu náo devia imaginar que cada membro fosse disposto c puxado isoladamente pelo titerciro (1) durante os diversos momentos da dança.

Cada movimento, disse ele, tinha um centro de gravidade; bastaria regê-lo no interior da figura; os membros, que nada eramexcetopêndulos, obedeciam porsi sós, mecanicamente, sem nenhuma ajuda.

Ele acrescentou que esse movimento cra muitosimples; que toda vez que ocentro de gravidade era movido $\mathrm{cm}$ linha reta os membros começavam a descrever cur vas e que, amiúde, quandosacudidode uma forma meramente acidental, otodocra arrastado numa espécie de movimento rítmico que se assemelhava à dança.

Essa observação me pareceu, a princí. pio, lançar alguma luz sobre o prazer que ele pretendia encontrar no teatrode marionetes. Entrementes, eu näosuspeitava ain- da, nem de longe, das consequêencias que iria tirardaí, mais tarde.

Perguntei-lhe se acreditava que 0 titereiroque regia os bonecos devia ser ele próprio um dançarinoou, ao menos, teralguma idéia dobelo na dança.

Ele me redargüiu que, embora a coisa fosse fácil por seu lado mecânico, năo seguia daí que pudesse ser acionada inteiramente sem osentimento.

A linha, que o centro de gravidade tinhade descrever, era na verdade muitosimples e, em sua opinião, na maioria das ve. zes, reta. Nos casos em que fosse encurvada, a lei de sua curvatura era pelo menos de primeira ou, no máximo, de segunda ordem; e também nesse último caso apenas elíptica, forma de movimentoque era natural para as extremidades do corpo humano (devidoàs juntas)em geral c, portanto, não requeria muita arte ao titereiro, para consigná-la.

Em compensação, essa linha era, de outrolado, algomuito misterioso. Pois nada maiscra senáo caminhotomadopcla alma do dançarino, c ele duvidava que fosse possivel encontrá-la de outro modo a nảo ser que o titereiro se colocasse no centro de gravidade da marionete, isto é, em outras palavras, que dançasse.

Repliquei que o trabalho deste se me havia apresentadocomoalgobastante maquinal (2), alguma coisa como virar uma manivela que toca um realejo.

"De maneira alguma", respondeu ele, "ao contrário, os movimentos de seus dedoscomportam-se em relaçãoao movimento dos títeres de forma bastante artificial, um pouco como os números $\mathrm{em}$ relaçáo a seus logaritmos, ou a assíntota $\mathrm{cm}$ relação à hipérbole".

Entrementes, expressou a crença de que lambém essa última fraçâo de cspírito, da qual falara, poderia ser removida das marionctes, que sua dança poderia ser inteiramente transferida para o reino das forças mecánicas $\mathrm{e}$ produzida por meio de uma manivela, tal como cu imaginara.

Externeimeuassombroem verqueatençî́o ele dedicava a essa modalidade de bela. arte, inventada para a plebe. Nảo sóque a julgasse capaz de um desenvolvimentosu. perior, mas que até ele próprio parecesse ocupar-se disso.

Ele sorriu e disse que ousava afirmar que, se algum mecânico(Mechanikus) quisesse construir-lhe uma marionete de acordo com as exigencias que tinha $\mathrm{cm}$ mente 
fazer-lhe, apresentaria uma dança, com o títere, que nem ele próprio nem qualquer destro dançarino de seu tempo, inclusive Vestris, estariam em condiçổes de igualar.

"Já ouviu falar", disse, enquantoeu, em silêncio, lançava oolhar para o chẫo, "dessas gâmbias mecânicas que artistas ingleses manufaturam para os infelizes que perderam suas pernas?"

Eu disse: nåo, semelhantes coisas nunca me apareceram diante dos olhos.

"Sinto muito", replicou, "pois se eu the disser que esses infelizes dançam com elas, receio muito que nāo creia em mim. Oque digo, dançam? A esfera de seus movimentosé, na verdade, muito limitada, mas aqueles movimentos que ainda permanecem sob o seu comando desenvolvem-se com uma serenidade, leveza e graça que pasmam todo espíritopensante".

Observei, brincando, que, sendo assim, tinha encontrado o homem que procurava. Pois o artista que estivesse em condiçōes de construir uma perna tão notável seria indubitavelmente capaz de montar-lhe toda uma marionete, de conformidade com suas exigências.

"Quais", disse eu, quando oviolhando para o châo, algo embaraçado, "quais, neste caso, são as exigências que o senhor faz à sua maestria?"

"Nenhuma", replicou ele, "que já não se encontre aqui: simetria, mobilidade, leveza; tudo isso, porém, em um grau mais elevado e especialmente segundo uma ordem mais natural dos centros de gravidade".

"Eque vantagem teria esse títere sobre dançarinos vivos?"

"Que vantagem? Primeiramente, uma vantagem negativa, meu excelente amigo, istoé, a de que nunca seria afetado. Pois a afetação aparece, comoosenhor sabe, quando a alma (vis motrix) se acha $\mathrm{em}$ algum outro ponto que nãoo do centro de gravidade do movimento. Uma vezque o titereiro, na realidade, por meio do fio ou arame, não tem em seu domínio nenhum outro ponto exceto esse, todos os demais membros são, portanto, o que devem ser, mortos, puros pêndulos que obedecem à mera lei da gravitação; uma excelente qualidade, que buscamos debalde na maioria de nossos bailarinos.

"Observe somente aquela dançarina P...", continuou, "quando ela representa Dafne e, perseguida por Apolo, volta-se para fitá-lo; sua alma está sediada na vértcbra da espinha; ela se curva como se quisesse quebrar, qual uma náiade da escola de Berninc. Observe ojovem F... quando, como Páris, ele se coloca entre as três deusas e entrega a maçã a Vênus: sua alma (é terrível olhálo) está sediada no cotovelo.

"Tais enganos", acrescentou, interrompendo-se, "são inevitáveis, desde que comemos da árvore do conhecimento.Sim,o Paraíso está a ferrolhado e oquerubim, atrás de nós; temos de fazer a viagem ao redor do mundoe verificar se não está, talvez, aberto, algures, por trás".

Eu ri. Certamente, pensei, o espírito não pode errar lá onde nâo existe espírito nenhum. Reparei, contudo, que ele tinha mais coisas nocoração, e pedi-lihe que prosseguisse.

"Ademais", declarou, "esses bonecos têm a vantagem de serem antigraves. Nada sabem da inércia da matéria, esta propriedade a mais antipódica à dança, porque a força que os ergue no ar é maior que a força que os mantém agrilhoados à terra. O que não daria a nossa boa $G$... se fosse sessenta libras mais leve, ou se um peso dessa grandeza viesse ajudá-la em sua piruetas? Os títeres necessitam apenas do chāo, comoos elfos, para tocá-lo e revivificar o impulso dos membros, pelo instante de detençẩo; nós precisamos dele para repousar nele e nos recuperarmos do esforço da dança; um momento que evidentemente não é em si dança, ecom oqual nada se pode fazer exceto fazê-lodesaparecer, se possivel".

Eu disse que, por mais habilmente que conduzisse também a questāo de scus paradoxos, jamais me levaria a crer que num manequim mecânico poderia haver mais graça que na estrutura do corpo humano.

Ele replicou que seria simplesmente impossível para o homem alcançar nisso, sequer aproximadamente, o manequim. Só Deus poderia, em tal terreno, medir-se com a matéria; $\mathrm{e}$ aqui reside o ponto $\mathrm{em}$ que as duas extremidades do mundo anular se interligam.

Eu me sentia cada vez mais espantado, e nẩo sabia o que deveria dizer diante de asserçồes tẫo singulares.

"Parecia", redargüiu ele, enquanto tomava uma pitada de rapé, "que cu nẩo lera com atençâoo terceiro capítulo do Livro de Moisés; e quem nảo conhecesse este periodo primeiro de toda a cultura humana, com tal pessoa não se poderia realmente falar sobre os subseqüentes c, muito menos, sobre os derradeiros". 


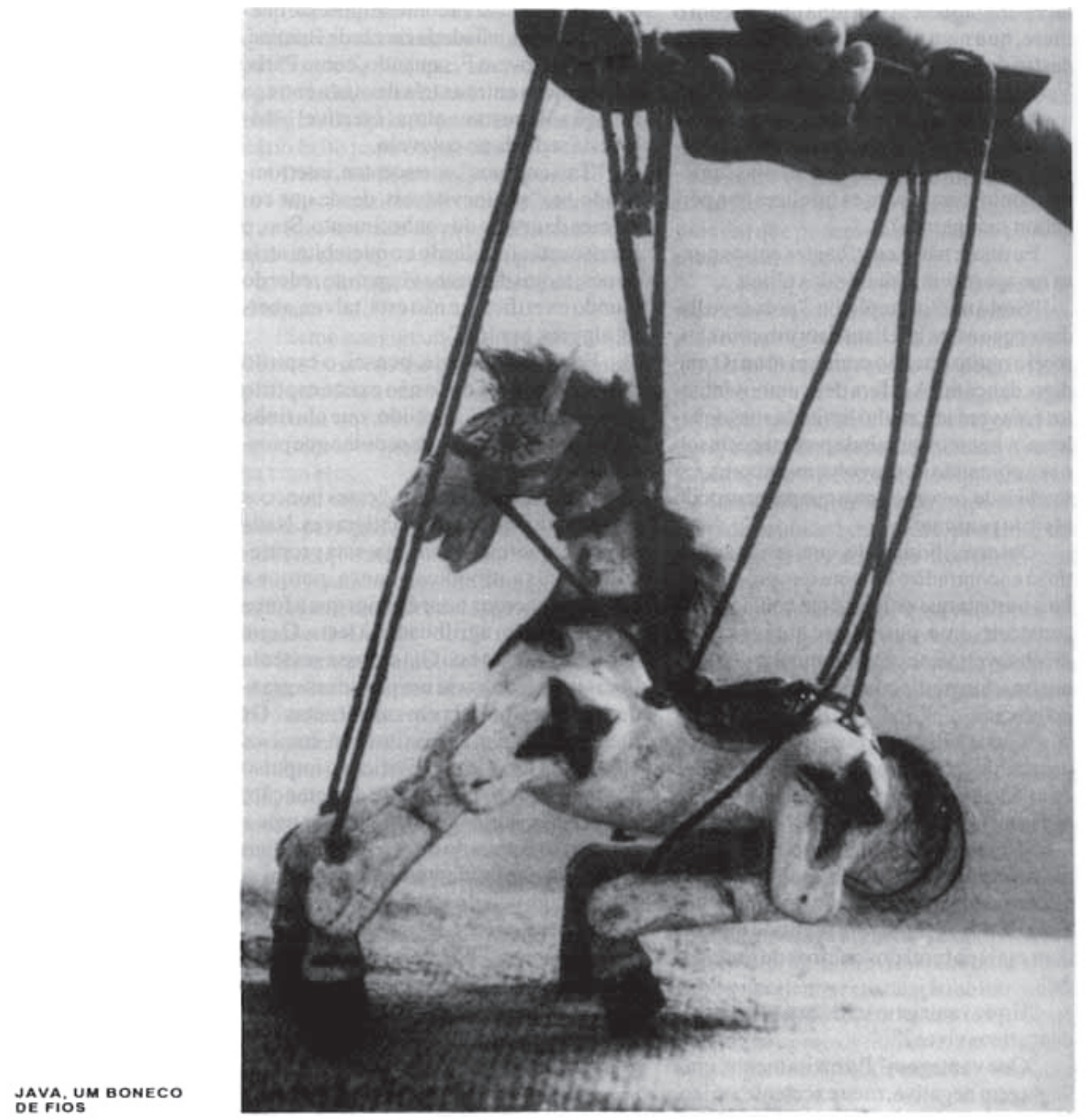

Disse-lhe saber muito bem que desordens na graça natural do homem a consciência preparava. Um moço de meu conhecimento, por um mero reparo, como que perdera a inocência diante de meus próprios olhos e em seguida nunca mais recuperara o paraíso desta inocência, a despeito de todos os esforços imagináveis. "Mas", adicionei, "que conseqüências pode o senhor extrair daí?"

Ele me perguntou a que incidente eu me referia.

"Há cerca de três anos", contei, "estava eu me banhando em companhia de um jovem, sobre cuja cultura entāose difundia maravilhoso encanto. Poderia andar pelos seus dezesseis anos, e só de muito longe seria possível perceber, suscitados pelo favor das mulheres, os primeiros traços de vaidade. Acontecera que pouco antes, em Paris, havíamos visto o jovem que extrai uma estilha do pé; a moldagem dessa estátua é bem conhecida e figura na maioria das coleçōes alemãs. Umolhar que ele, naquele instante, ao pôr o pé sobre o escabelo para enxugá-lo, atirou ao grande espelho, olembrou disso; sorriu e disse-me que descoberta efetuara. De fato, naquele instante eu também notara o mesmo; todavia, fosse para comprovar a certeza da graça que o habita- 
va, fosse para acolher sua vaidade de modo algo salutar, sorri e retruquei que ele estava provavelmente vendoespíritos! Enrubesceu c levantou o pé pela segunda vez para mo mostrar; mas a tentativa falhou, como seria fácil de prever. Confuso, levantou opé uma terceira, uma quarta, levantou-obem mais de umas dez vezes: em vảo! Era incapaz de repetir o mesmo movimento. O que estou dizendo? Os movimentos que fazia tinham um elemento tẩo cômico que me foi difícil conter oriso.

"Desse dia em diante, quase a partir do próprio instante, uma inexplicável transformação verificou-se naquele moço. Começou a ficar diante do espelho o dia inteiro, $\mathrm{e}$ um encanto após outro o abandonou. Um poder invisível e inexplicável parecia estender-se, qual uma rede de ferro, em torno do livre jogo de seus gestos, e decorridoum ano, năo havia mais traço de encanto a descobrir nele, aquele encanto que tanto deliciara os olhos das pessoas que o circundavam. Mesmo agora, ainda vive alguém que foi testemunha do estranho e infeliz incidente, e que poderia confirmá-lo, palavra por palavra, como eu lho contei."

"Neste enscjo", disse o Sr. C....amavelmente, "devo narrar-lhe outra história que, osenhor entenderá facilmente, também tem aqui o seu lugar.

"Em minha viagem à Rússia, encontrei-me numa herdade de campo doSr.de G..., um nobre livônio, cujos filhos precisamente entäo se exercitavam na arte da esgrima. O mais velho, especialmente, que acabara de retornar de uma universidade, considerava-se um virtuose, e certa manhã, em seu quarto, ofereceu-me um florete. Esgrimimos, mas sucedeu que eu era superior a ele; a paixâo somou-se à sua confusâo; quase toda estocada que eu desfechava lograva êxito e seu florete voou, ao fim, para um canto. Meio zombeteira, meio sentidamente, disse, enquanto olevantava, que encontrara seu mestre; mas tudo neste mundo encontra o seu, e em seguida quis levar-me ao meu. Os irmâos riram-se às gargalhadas e gritaram: Avante! Avante! Ao barracảo de madeira!, e me pegaram pela măoe me conduziram até um urso, que o Sr. de G..., pai deles, estava criando no pátio.

"Quando, para o meu assombro, me vi diante dele, o urso estava $\mathrm{em}$ pé, sobre as patas traseiras, como lomboencostado $\mathrm{cm}$ uma estaca, à qual fora acorrentado, a garra direita erguida, pronta para tudo, e olhou- me nos olhos: era sua posição de esgrimista. Eu não sabia se estava sonhando quando me vi em face de um tal adversário; mas, ataque, ataque!, disse o Sr.de G..., e veja se consegue derrotá-lo. Havendo me recobrado um pouco de minha perplexidade, investi com o florete contra o urso; este fez um ligeiro movimento com a pata $\mathrm{e}$ aparou ogolpe. Tentei enganá-lopor meiode fintas; o urso nảo se mexeu. Tornei a acometê-lo com uma habilidade do momento; eu teria acertado o peito de um homem, infalivelmente: o urso fez um movimento muito breve $\mathrm{e}$ aparou ogolpe. Eu me achava agora quase na posiçăo do jovem $\mathrm{Sr}$. de G... A seriedade do urso era tal que chegou a roubar-me a confiança em mim mesmo. Estocadas e fintas sucederam-se, eu gotejava suor: $\mathrm{cm}$ văo! Nảo sóo urso, qual o melhor esgrimista do mundo, aparava todas as minhas estocadas, mas (c nisso nenhum esgrimista seria capaz de imitá-lo) nem sequer entrava nas fintas: olho nos olhos, comose pudesse ler neles minha alma, permanecia ali parado, a garra erguida, pronta para tudo, e sempre que meus golpes nảo cram desfechados seriamente, nãose movia.

"Osenhor acredita nessa história?"

"Perfeitamente", exclamei, com jubiloso aplauso, "de qualquer estranhoque viesse, dar-lhe-ia crédito, tâoverossímil ela é; quanto mais vindo do senhor!"

"Pois bem, meu excelente amigo", disse o Sr. C..., "agora está de posse de tudo o que é necessário para entender-me. Vemos que, à medida que a reflexăo se torna mais obscura e fraca no mundoorgânico, a graça emerge ai tanto mais brilhante e dominante. Mas assim como a intersecçăo de duas linhas, de um mesmo lado de um ponto, depois de passar através do infinito, encontra-se de súbito do outro lado; ou, como a imagem doespelho côncavo, após ter desaparecido no infinito, está de repente mais uma vez diante de nós, assim reaparece novamente agraça, depois que oconhecimento tenha passado comoque por um infinito, de tal modo que, ao mesmo tempo, surge no grau mais puro naquela estrutura corporal humana que ou nảo tem consciência nenhuma ou tem uma consciência infinita, isto é, no manequim, ou no Deus".

"Portanto", disse eu, algo confuso, "precisariamos comer de novo da árvore do conhecimento para recair noestadode inocência?"

"Naturalmente", respondeu cle, "este é oúltimo capítulo da história do mundo". 